\title{
Myelodysplastic Syndrome with Excess Blasts and Fibrosis
}

National Cancer Institute

\section{Source}

National Cancer Institute. Myelodysplastic Syndrome with Excess Blasts and Fibrosis. NCI Thesaurus. Code C82595.

Myelodysplastic syndrome with excess blasts associated with significant reticulin fibrosis of the bone marrow. 